\title{
RHEOLOGICAL INVESTIGATION OF RUBBER BITUMEN CONTAINING VARIOUS WAXES AS WARM MIX ADDITIVE
}

\author{
PÉTER GERGÓa ${ }^{*}$, ANDRÁS HOLLÓa ${ }^{\text {, ANDRÁS GEIGER }}{ }^{\mathrm{b}}$
}

\begin{abstract}
The aim of this study is to investigate the effect of various wax type warm mix additives on the rheological properties of Chemically Stabilized Rubber Bitumen (CSRB). The rubber bitumen samples were prepared by the modified wet process (HU 226481) and the bitumen tests were carried out according to the relevant standards. Two types of warm mix additives (polypropylene wax - produced by thermal cracking of polypropylene and Fischer-Tropsch wax) with different concentrations (1.0\%, 3.0\%, 5.0\%, $7.0 \%$ by weight) were used in our research. The influence of these warm mix additives on the rheological properties was evaluated by Dynamic Shear Rheometer (DSR) test. Multiple-stress creep and recovery (MSCR) test was also used for the determination of percent recovery and non-recoverable creep compliance of wax-modified and neat asphalt rubber samples. According to the results of DSR tests the addition of the Fischer-Tropsch wax resulted a higher complex modulus (thereby stiffness) and favourable higher recovery values based on MSCR tests unlike the addition of polypropylene wax.
\end{abstract}

Keywords: warm mix additive, asphalt rubber, rheological properties, MSCR

\section{INTRODUCTION}

The major source of pollution in asphalt application originates from its production and lay down. Moreover, the energy consumption of the hightemperature Hot Mix Asphalt (HMA) technologies is also large. The lower energy consumption of road construction and thus lower greenhouse gas emission can be achieved with the production of so-called warm mix asphalt [1]. The most

\footnotetext{
a University of Pannonia, Faculty of Engineering, MOL Department of Hydrocarbon and Coal Processing, 10 Egyetem street, HU-8200, Veszprém, Hungary

b MOL Hungarian Oil and Gas PIc., 2 Olajmunkás street, HU-2440, Százhalombatta, Hungary

*Corresponding author: gergop@almos.uni-pannon.hu
} 
common manufacturing technologies of Warm Mix Asphalt (WMA) can be classified into three groups based on the technology used. In the first group, there are water-based, foaming technologies. The second group contains organic additives applying technologies. In the third group there are chemical additives applying technologies. The most commonly used chemical additives include waxes produced by Fischer-Tropsch (FT) synthesis, fatty acid amides, and Montan wax [2-3].

Applying the latter additives during the temperature rise the wax will melt and remains above the melting point and because of the lower viscosity it decreases the viscosity of the whole mixture. During cooling the asphalt mixture, the applied additive solidifies - distributed uniformly in the mixture, in microscopic form. These crystalline particles increase the rigidity of the mixture similarly to the fiber reinforced materials.

An important requirement of this process is the selection of the right additive type, which avoids problems that can occur with the temperature [4]. One such problem may arise if the wax has a melting point lower than the temperature of application and therefore care must be taken in selecting the wax having the strength and toughness on the application temperature. In addition, the selection of the wax having appropriate properties reduces the low temperature embrittlement problems [5].

Waxes used in these technologies have generally high molecular weight, paraffins having high carbon numbers $(\mathrm{C} 45<)$ and a melting point between 80 and $120^{\circ} \mathrm{C}$ are applied [6]. Depending on the technology a small amount of these waxes, about $2-4 \%$ are applied concerning the total weight of the bitumen binder. The available mixing and processing temperature decrease is approximately $20-30^{\circ} \mathrm{C}$.

In addition to the three main wax types experiments are conducted with waxes originating from waste polypropylene pyrolysis or cracking in order to decrease the application temperature of hot asphalt technologies [7].

Rubber bitumen is a special type of modified bitumen. Thanks to the crumb rubber in the composition, it has better characteristics than the base bitumen, similarly to the conventional Polymer modified Bitumen (PmB). In addition to this because of the partly diluted rubber particles the traffic noise is lower, the pavement is more flexible, it has better resistance to fatigue and load, in the meantime it has outstanding cold weather resistance. The stability of the rubber bitumen produced according to the modified wet process is better compared to the conventional rubber bitumen, namely it has low separation tendency [8-9].

The viscosity of CSRB is lower compared to conventional rubber bitumen and similar to the well-known PmB's and higher than base bitumen, thus it requires higher mixing temperature. Because of this in case of CSRB the mixing 
temperature and the decrease of the viscosity are important R\&D target. Because of the above reasons the application of WMA additives are also recommended.

Different WMA additives were recently studied by other researchers in rubber bitumen. E.g. 2-4\% Fischer-Tropsch wax addition could result 10$30^{\circ} \mathrm{C}$ lower mixing temperature in similar asphalt rubber binder [10].

\section{RESULTS AND DISCUSSION}

In order to determine the base properties of the samples the softening point, penetration, Fraass breaking point and storage stability were measured.

Based on the changes in the softening point, the admixing of polypropylene wax reduced this value of samples. Increasing the concentration, the effect has increased slightly (figure 1).

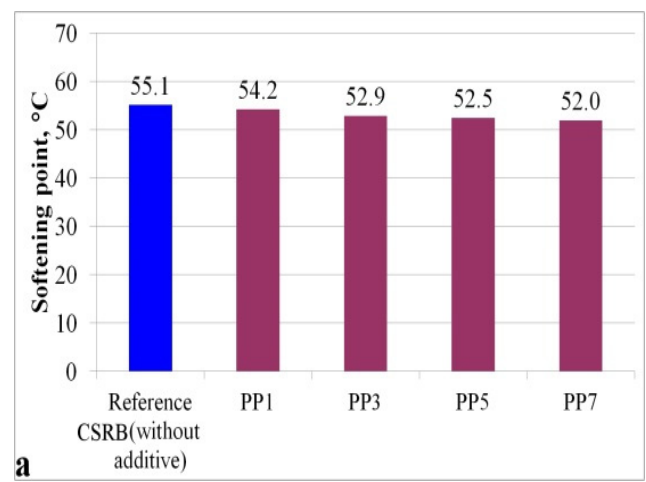

(a) Polypropylene wax

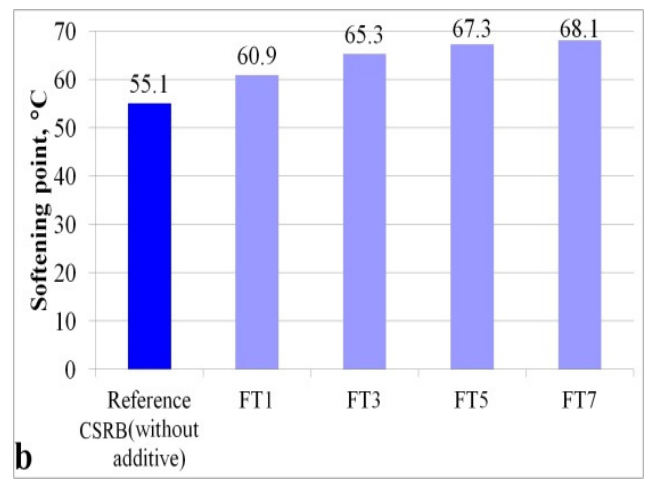

(b) FT wax

Figure 1. Influence of polypropylene wax and FT wax on softening point of the samples

The mixing of polypropylene wax had an impact also on the penetration of the samples (figure 2.). This value increased for higher doping concentration (5.0 to $7.0 \%$ ); the effect was more significant. In contrast the FT wax highly hardened the samples, thus reduced the penetration value, but due to this effect the samples were also brittle (figure 3). 


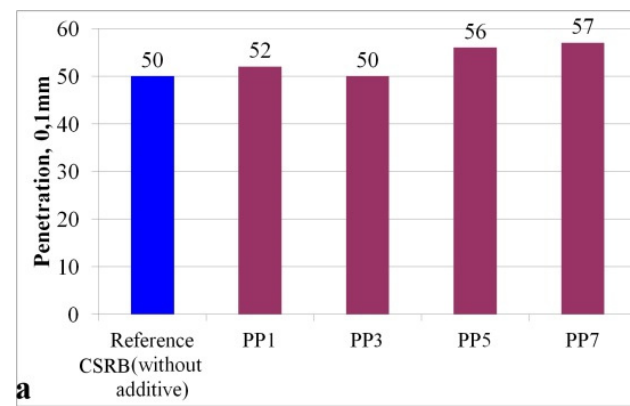

(a) Polypropylene wax

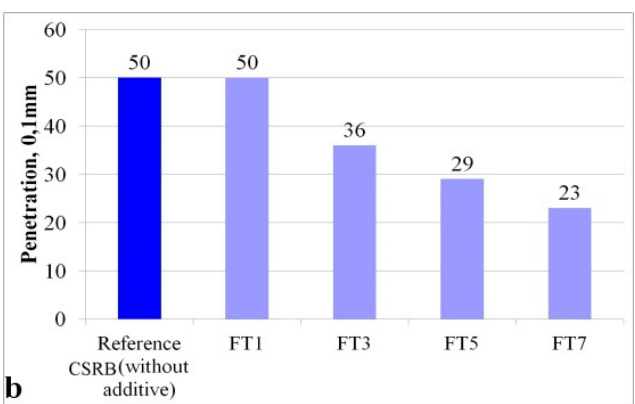

(b) FT wax

Figure 2. The influence of PP heavy residue and FT wax on the penetration of the samples

Based on the Fraass breaking point of the samples which characterizes the cold side properties; the mixing of polypropylene wax was more favourable compared to the FT wax, because in this case, to a lesser extent increased the breaking point with the additive concentration. This effect may have caused by the olefin content of polypropylene wax and the resulting higher pour point compared to the pure paraffin type FT wax (figure 3).

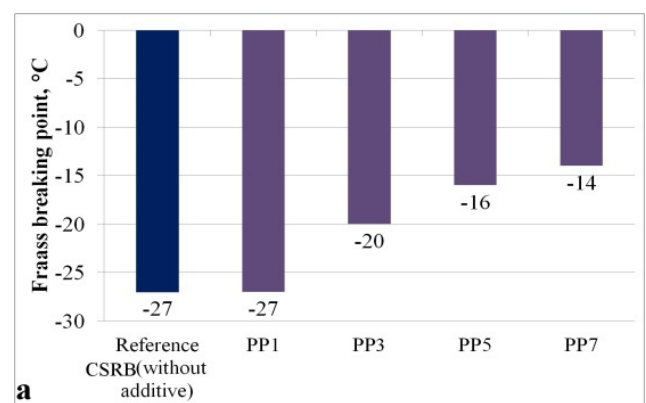

(a) Polypropylene wax

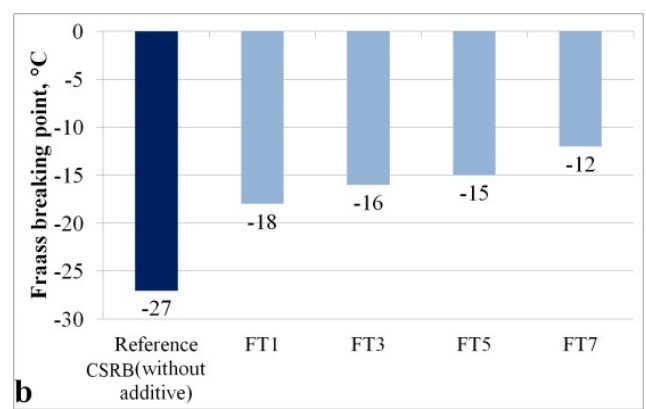

(b) FT wax

Figure 3. The influence of polypropylene wax and FT wax on Fraas breaking point of the samples

To characterize the storage stability of bitumen, the softening point difference between the upper and lower section of bitumen are measured after storage. However, this basic test method is not always characterising correctly the application properties of the samples. This is especially true for the multi-component systems such as modified bitumen containing different modifying agent with different functions, composition and thus different characteristics. 
Both the studied additives slightly deteriorated the stability. Based on the measured values significant differences were not experienced between the two additives used. The stability of the samples reduced (softening point difference increased) slightly by increasing the concentration of the waxes (figure 4).

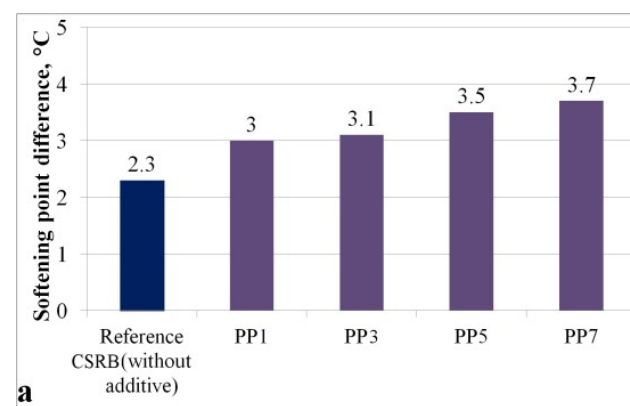

(a) Polypropylene wax

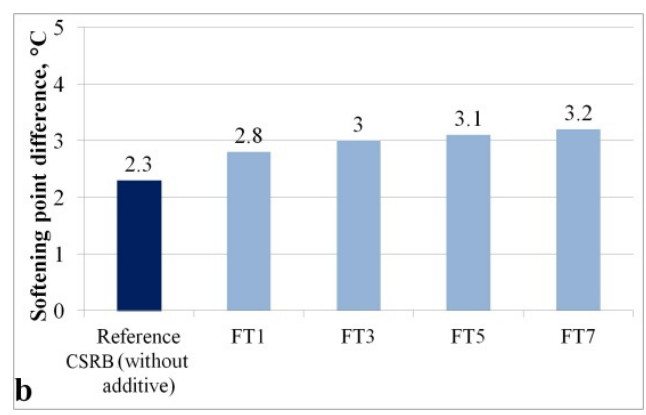

(b) FT wax

Figure 4. The influence of polypropylene wax and FT wax on the storage stability (softening point difference) of the samples

We also investigated the high temperature viscosity of the lower and upper part of the stored samples. Due to the increased sedimentation, great differences of the viscosity were measured between the lower and upper part of the samples containing the polypropylene wax on both investigated temperatures. This difference is increased by increasing the additive concentration. In case of measuring FT wax containing patterns, we have also seen separation, however, the trend was different (figure 5).

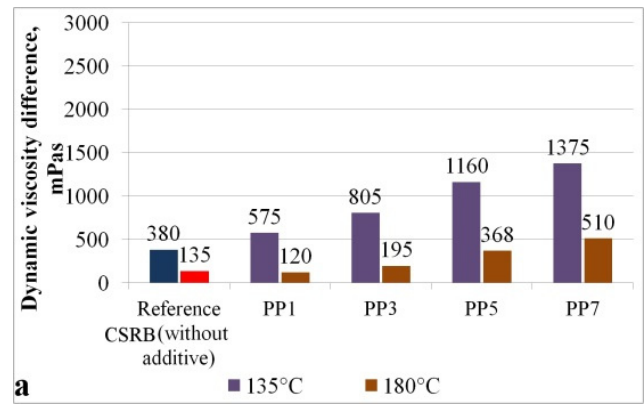

(a) Polypropylene wax

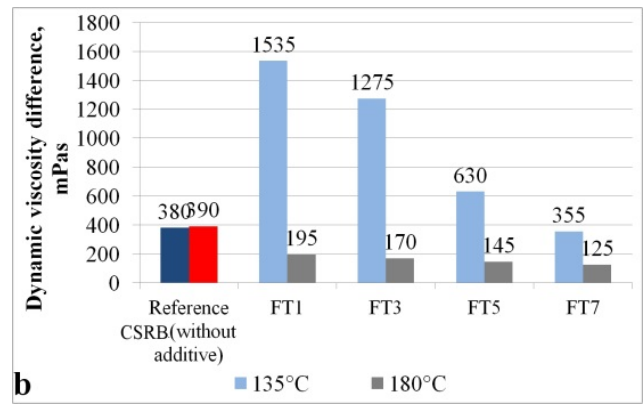

(b) FT wax

Figure 5. The influence of polypropylene wax and FT wax on the storage stability (dynamic viscosity difference) of the samples 
The viscosity reducing effect of the flow modifiers was tested on the compaction $\left(135^{\circ} \mathrm{C}\right)$ and the mixing $\left(180^{\circ} \mathrm{C}\right)$ temperatures of the asphalt mixture as well. Based on the results both additives have favourable viscosity decreasing effect; the result of polypropylene wax admixing was slightly lower than the FT wax admixing (figure 6).

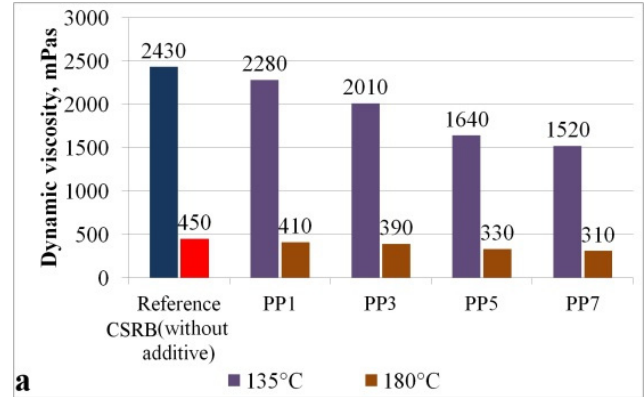

(a) Polypropylene wax

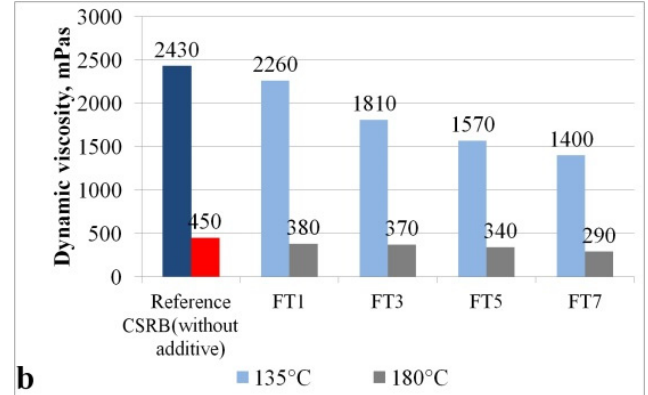

(b) FT wax

Figure 6. The influence of polypropylene wax and FT wax on the dynamic viscosity of the samples

We determined the changes of complex modulus (stiffness) for polypropylene wax containing samples varying the temperature. We found that this value decreased in the whole temperature range. In the lower temperature range (below $35^{\circ} \mathrm{C}$ ) with increasing the doping concentration, the stiffness value approached the value of the reference sample. In contrast, with the application of the FT wax, the stiffness increased greater extent below $70^{\circ} \mathrm{C}$ because its plastomer type (figure 7 ).

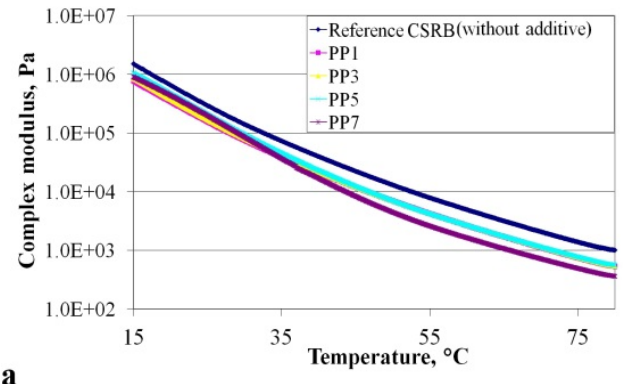

(a) PP heavy residue

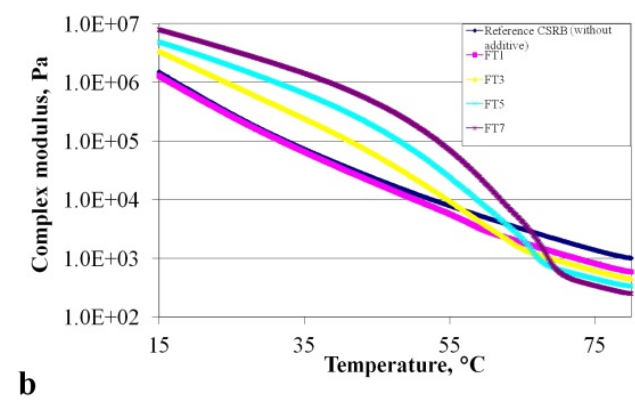

(b) FT wax

Figure 7. The influence of polypropylenewax and FT wax on the complex modulus of the samples 
The multiple creep relaxation test provides information on elastic, resilient properties of the samples. During this test, the sample is first loaded with a force of $100 \mathrm{~N}$ for 1 second, followed by a 9 seconds-long relaxation phase. This cycle was performed 10 times, and then the force increased to $3200 \mathrm{~N}$ and a further 10 cycles were performed as previously mentioned monitoring the changes of deformation, according to the MSZ EN 16659 standard [11]. The samples which contained polypropylene wax additive were more susceptible to deformation. The $100 \mathrm{~N}$ cycles resulted less deformation, while the samples were being greatly deformed during the $3200 \mathrm{~N}$ cycles. In case of addition of the FT wax opposite effect was observed. When the additive concentration increased, susceptibility to deformation reduced compared to the reference sample due to the intake of hard parts (figure 8-9).

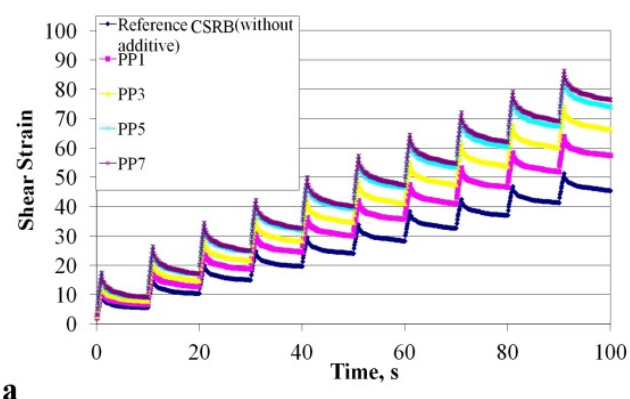

(a) $100 \mathrm{~N}$

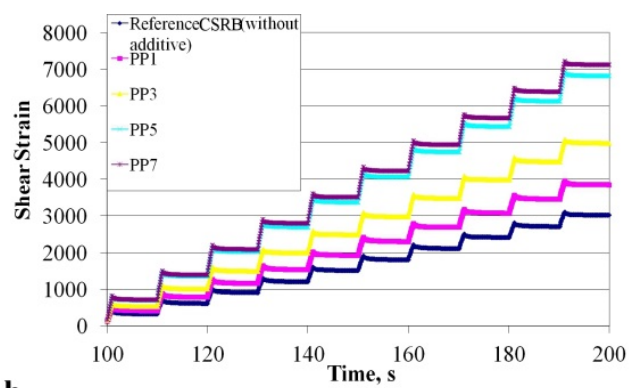

(b) $3200 \mathrm{~N}$

Figure 8. The results of multiple creep relaxation tests of polypropylene waxe modified samples

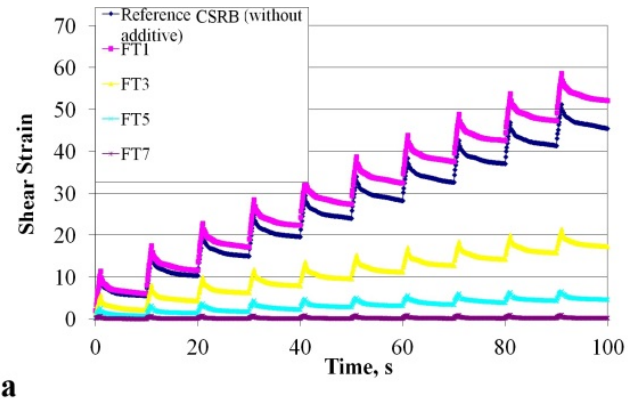

(a) $100 \mathrm{~N}$

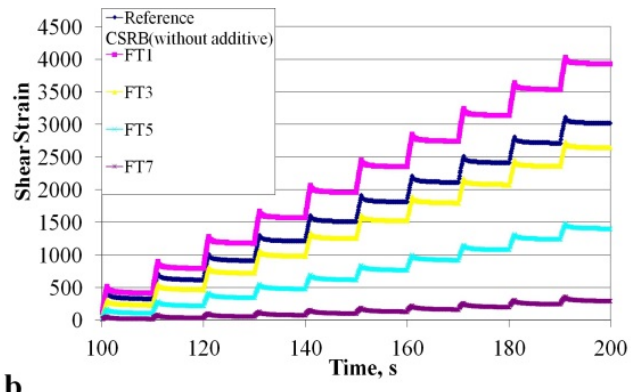

(b) $3200 \mathrm{~N}$

Figure 9. The results of multiple creep relaxation tests of FT wax modified samples 
The amount of recovery was also calculated. The elasticity of polypropylene containing samples were about the same during the $100 \mathrm{~N}$ load, however, the value fell short of the reference sample of over $3200 \mathrm{~N}$ loads. In case of FT wax containing samples, when the concentration increased; the maximum deformation is reduced, however, based on the favourable relaxation characteristics of the matrix the residual deformation was less, so the samples showed better reversion (figure 10-11).

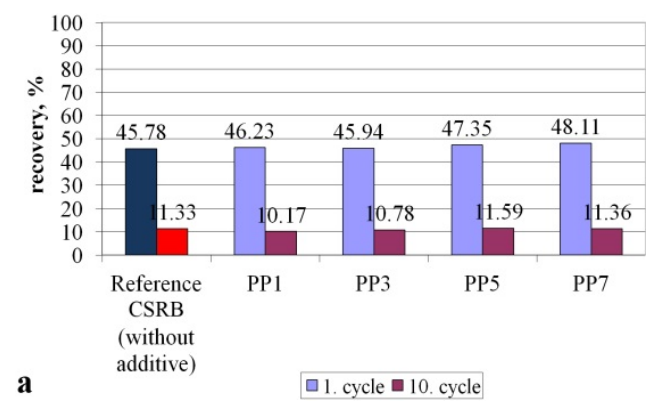

(a) $100 \mathrm{~N}$

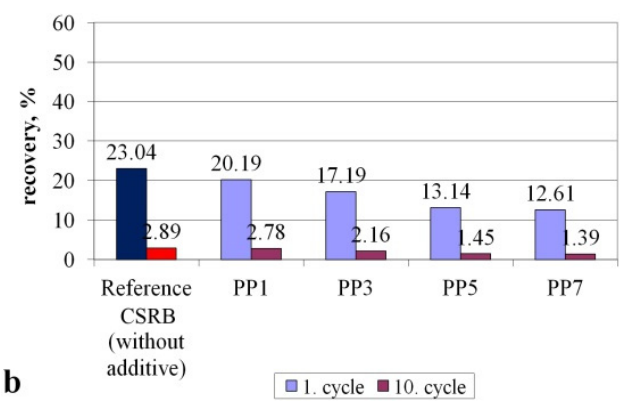

(b) $3200 \mathrm{~N}$

Figure 10. The recovery of polypropylene wax modified samples

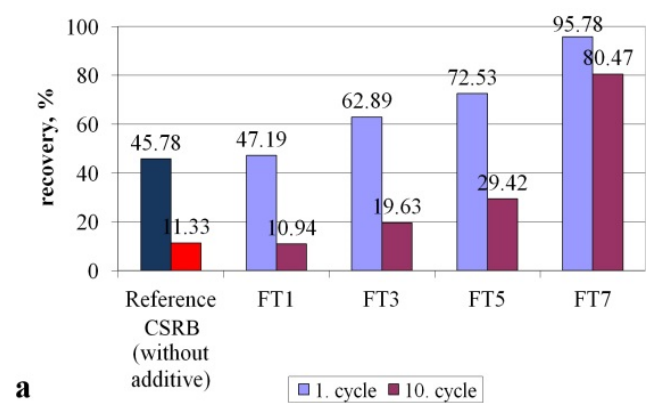

(a) $100 \mathrm{~N}$

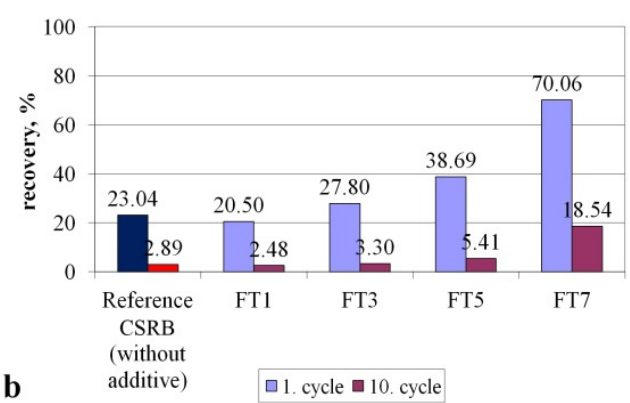

(b) $3200 \mathrm{~N}$

Figure 11. The recovery of FT wax modified samples

The application of polypropylene wax at 1 and $3 \%$ concentration increased the modulus (stiffness) at $15^{\circ} \mathrm{C}$ and $10 \mathrm{~Hz}$ load, but the further increase in additive concentration largely reduced this value due to the weak stiffness of the additive. The FT wax increased this value at all concentrations, but due to the increasing effect, the samples become rigid (figure 12). 


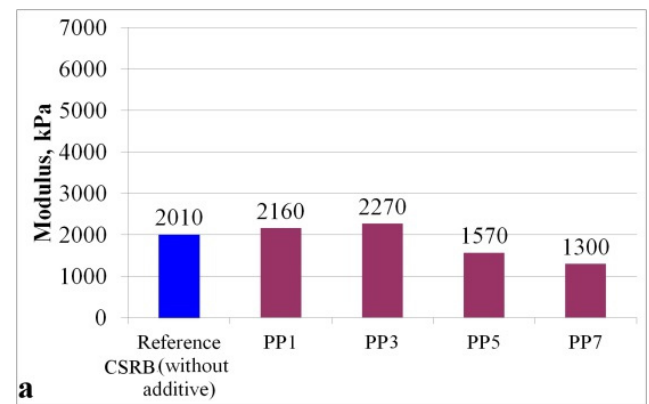

(a) Polypropylene wax

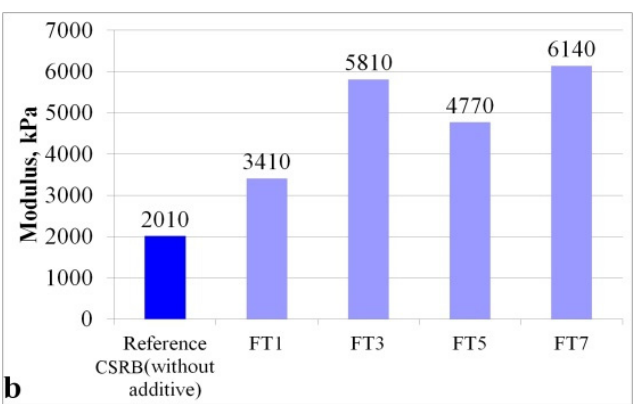

(b) FT wax

Figure 12. The influence of polypropylene wax and FT wax on the modulus of the samples

\section{CONCLUSIONS}

As a result, it can be concluded that both polypropylene wax and Fischer-Tropsch wax favourably reduced the viscosity of chemically stabilized rubber bitumen at high temperature $\left(135-180^{\circ} \mathrm{C}\right)$. With the application of these wax type additives, the breaking point of the samples significantly deteriorated.

In the rheological measurements we found greater changes in properties and different behaviour of the samples.

The resistance to deformation improved with the use of FischerTropsch wax in medium asphalt temperature $\left(15^{\circ} \mathrm{C}\right)$, the modulus also increased, which resulted the improvement of resistance to loads, nevertheless the rigidity of the samples increased. In contrast, the polypropylene wax modified samples were sensitive to deformation and their elastic recovery values also reduced.

Regarding the industrial application further studies are needed to determine the optimal concentration of the additives for these binders meeting the standard properties of the rubber bitumen. These tests are ongoing.

\section{EXPERIMENTAL SECTION}

The following materials were used in the study to carry out the experiments: Sasolwax $\mathrm{C} 80$ hard wax (congealing point: $80-85^{\circ} \mathrm{C}$, drop point: $88^{\circ} \mathrm{C}$ ) from Novochem Ltd. (Overlack Group) and polypropylene wax made by thermal cracking of polypropylene (drop point: $58^{\circ} \mathrm{C}$ ). The base material was a commercial, Chemically Stabilized Rubber Bitumen (CSRB) produced 
according to the modified wet process (HU 226481) [12], by MOL Plc., meeting the requirements of the Hungarian MSZ 930:2015 standard [13].

Different concentrations of the warm mix additives $(1.0 \%, 3.0 \%, 5.0 \%$, $7.0 \%$ by weight) were used in our research program. The influence of the warm mix additives on the rheological properties was evaluated by Dynamic Shear Rheometer (DSR) tests with an Anton Paar MCR301 Dynamic Shear Rheometer. Complex modulus $\left(G^{*}\right)$ changes of each bitumen samples at $15^{\circ} \mathrm{C}$ in various frequency load were measured compared to the asphalt stiffness and fatigue tests. The measured properties are shown in Table 1.

Table 1. Investigated parameters of the bitumen samples

\begin{tabular}{|l|c|}
\hline \multicolumn{2}{|c|}{ Standard tests } \\
\hline Properties & Standard \\
\hline Softening point, ${ }^{\circ} \mathrm{C}$ & MSZ EN 1427 \\
\hline Penetration, $0,1 \mathrm{~mm}$ & MSZ EN 1426 \\
\hline Fraass breaking point, ${ }^{\circ} \mathrm{C}$ & MSZ EN 12593 \\
\hline Dynamic viscosity, $\mathrm{mPas}$ & MSZ EN 13302 \\
\hline Storage stability, ${ }^{\circ} \mathrm{C}$ & $\mathrm{MSZ}$ EN 13399 \\
& $\mathrm{MSZ}$ EN 1427 \\
\hline Multiple Stress Creep Recovery $\left(\right.$ at $\left.60^{\circ} \mathrm{C}\right)$ & $\mathrm{MSZ}$ EN 16659 \\
\hline Non-standard rheological tests & \\
\hline Temperature sweep $\left(80-15^{\circ} \mathrm{C}\right.$ temperature range, $10 \mathrm{~Hz}$ frequency, $1^{\circ} \mathrm{C}$ cooling rate) \\
\hline Frequency sweep (at $15^{\circ} \mathrm{C}, 0,1-100 \mathrm{~Hz}$ frequency range) \\
\hline
\end{tabular}

\section{ACKNOWLEDGMENTS}

This work was supported by the University of Pannonia and MOL Hungarian Oil and Gas Co. The authors appreciate the technical and financial support. 


\section{REFERENCES}

1. A. Almeida-Costa, A. Benta, Journal of Cleaner Production, 2016, 112, 23082317.

2. M.C. Rubio, G. Martínez, L. Baena, F. Moreno, Journal of Cleaner Production, 2012, 24, 76-84.

3. J. D’Angelo, E. Harm, J. Bartoszek, G. Baumgardner, M. Corrigan, J. Cowsert, T. Harman, M. Jamshidi, W. Jones, D. Newcomb, B. Prowell, R. Sines, B. Yeaton, "Warm-Mix Asphalt: European Practice. Report No.FHWA-PL-08-007." American Trade Initiatives, Alexandria, USA, 2008.

4. H.M.R.D. Silva, J.R.M. Oliveira, J. Peralta, S.E. Zoorob, Construction and Building Materials, 2010, 24, 1621-1631.

5. L. Shang, S. Wang, Y. Zhang, Y. Zhang, Construction and Building Materials 2011, 25, 886-891.

6. N. Bueche, "Warm Asphalt Bituminous Mixtures with Regards to Energy, Emissions and Performance" Young Researchers Seminar (YRS) LAVOCCONF-2010-002, Torino, Italy, 2009.

7. G.C. Hurley, B.D. Browell, "Evaluation of Sasobit for Use In Warm Mix Asphalt. NationalCenter for Asphalt Technology. Report 05-06.", Auburn University, Auburn, USA., 2005.

8. A. Geiger, A. Holló, G. Szalmásné Pécsvári, P. Fehér, MOL Group Scientific Magazine, 2012, 2, 54-61.

9. A. Geiger, L. Gáspár, A. Holló, M. Péter, R. Durgó, Cs. Csőke, S. Czibor, MOL Group Scientific Magazine, 2014, 2, 74-83.

10. A.M. Rodrigez-Alloza, J. Gallego, I. Perez, A. Bonati, F. Giuliani, Construction and Building Materials, 2014, 53, 460-466.

11. MSZ EN 16659:2016, "Bitumen and Bituminous Binders. Multiple Stress Creep and Recovery Test (MSCRT)", 2016.

12. HU 226481, Sz. Bíró, L. Bartha, Gy. Deák, A. Geiger, "Chemically stabilized asphalt rubber compositions and a mechanochemical method for preparing the same", 2009.

13. MSZ 930:2015 standard, "Bitumen and bituminous binders. Rubber modified bitumen. Requirements", 2015. 